\title{
TRÂNSITOS, AFIRMAÇÕES E NEGAÇÕES SOBRE A IDENTIDADE JAPONESA NO BRASIL
}

\section{MOBILITIES, AFFIRMATIONS AND NEGATIONS ABOUT THE JAPANESE IDENTITY IN BRAZIL}

\author{
Denise Akemi Hibarino ${ }^{1}$ \\ Guilherme Jotto Kawachi
}

\section{RESUMO}

O objetivo deste trabalho é discutir e contestar algumas questões relacionadas aos construtos de identidade e cultura em meio aos processos da imigração japonesa no Brasil, mais especificamente, no sul do país. Buscamos avaliar os efeitos de algumas medidas políticas para o desenvolvimento de estereótipos acerca de japoneses, especialmente considerando as tentativas de repressão e silenciamento perceptíveis em algumas dessas políticas. Interessa-nos, nessa perspectiva, observar as representações e discursos construídos na época do fluxo migratório japonês no Brasil em torno da figura/imagem do "estereótipo do japonês". Com isso, pretendemos, também, ponderar sobre como os movimentos de trânsitos, mobilidades e deslocamentos dos imigrantes podem ser refletidos nas suas representações identitárias, revelados simbolicamente por meio da linguagem, em construções discursivas.

Palavras-chave: linguística aplicada; imigração japonesa no Brasil; identidade; estereótipo.

\section{ABSTRACT}

The focus of this article is to address and argue about some issues related to the constructs of identity and culture in the Japanese immigration process in Brazil, mainly in the Southern parts of the country. We examined the effects of political measures for the development of Japanese stereotypes, especially considering some attempts of repression and the perceptible silencing in some of these policies. In this perspective, this paper also presents analysis of the representations and discourses built during the Japanese migration flow to Brazil regarding the character/image of the "Japanese stereotype". Therefore, it is also intended to present how the immigratory transit movements, mobilities and displacements can be reflected in their identity representations, symbolic revealed through language, in discursive constructions.

Keywords: Applied Linguistics; Japanese immigration in Brazili identity; stereotype.

\footnotetext{
" UFP, Curitiba (PR), Brasil. dhibarino@gmail.com; UNICAMP, Campinas (SP), Brasil. guilhermekawachi@gmail.com
} 


\section{INTRODUÇÃO}

A intensificação dos movimentos de globalização, os avanços tecnológicos e as tentativas de democratização de ferramentas digitais - considerando-se o advento da Internet - têm provocado mudanças de diversas ordens: sociais, culturais, educacionais, epistemológicas, geopolíticas, entre muitas outras.

Esse processo contínuo de desenvolvimentos em vários campos evidencia uma percepção de "encurtamento de distâncias" (HALL, 1998), trazendo a cabo uma gama de novas possibilidades, novos relacionamentos e novos modos de se relacionar, novas epistemologias, trânsitos ou mobilidades.

No que se refere aos movimentos de imigração, é preciso destacar que eles não ocorrem "apenas" em função das mudanças evidenciadas pela globalização. Há uma série de fatores históricos, territoriais e, principalmente, políticos que subjazem esses processos migratórios, atrelados, obviamente, às particularidades e motivações de cada grupo.

No entanto, existe uma relação direta entre processos de (i)migração e movimentos de globalização, na medida em que se nota que esses movimentos "não só integram e geram mestiçagens; também segregam, produzem novas desigualdades e estimulam reações diferenciadoras" (GARCIA CANCLINI, 2008, p. XXXI).

Torna-se certo, então, que todas as mobilidades decorrentes da era tecnológica - a era em que vivemos - são circundadas por profundas disparidades, que afetam tanto os próprios processos de idas e vindas inter/intraculturais e inter/intraterritoriais, quanto os discursos imbuídos nesse cenário. No âmbito deste trabalho, é esta perspectiva que nos interessa, enquanto estudiosos da linguagem: as representações culturais, sociais e identitárias (e as nossas percepções sobre essas representações) mediadas pela linguagem em contextos de trânsitos, mobilidades e (i)migrações. Já neste ponto, portanto, partimos da ideia de que discursos são representações posicionadas (FAIRCLOUGH, 2010), o que significa que observar e contestar documentos políticos oficiais acerca de processos migratórios implica, também, contestar discursos e, consequentemente, posicionamentos evidenciados por meio de construções discursivas.

Assim sendo, este trabalho é resultado de nossas reflexões sobre linguagem, cultura, identidade e políticas linguísticas em diferentes contextos. ${ }^{1}$ Dentre todos os temas pertinentes a esses conceitos, consideramos a questão dos imigrantes, em

1 Reflexões resultantes de nossa participação na disciplina "Educação Bilíngue", ministrada pela Profa Dra. Terezinha de Jesus Machado Maher, em 2011, no Instituto de Estudos da Linguagem (IEL) da Universidade Estadual de Campinas (Unicamp). 
particular a condição dos imigrantes japoneses no Brasil, uma das mais significativas, por revelar conflitos e negociações de identidade de sujeitos geralmente representados como desenraizados, idealizados e estereotipados (SAITO, 1961; NUCCI, 2000; BHABHA, 2005).

Além disso, outro motivo que fundamenta essa nossa escolha tem caráter puramente pessoal. Mesmo com histórias de famílias diferentes, somos ambos netos de imigrantes japoneses que se instalaram no sul e no sudeste do Brasil2. Nos nossos distintos percursos de infância e adolescência, tivemos contato tanto com familiares dessa descendência quanto com amigos e colegas de outras origens, como alemã, polonesa e italiana, o que possivelmente não é surpreendente diante do caráter fortemente mestiço e multicultural da população brasileira. Em meio a essa convivência marcada pela diversidade cultural (e também étnica/racial, identitária), tomávamos como certo que todos conviviam pacificamente, cada um respeitando a cultura e o espaço do outro.

Deste modo, a participação em diferentes comunidades de prática como a escola, festas típicas, casas de amigos e familiares e o contato com as diferentes línguas faladas pelos nossos avós/bisavós e pelos avós/bisavós de amigos levavam ao desenvolvimento de uma (falsa) impressão de histórias sem conflitos, de uma liberdade de expressão que parecia sempre existir e que fora concedida desde o momento em que os primeiros imigrantes chegaram ao país.

Desta maneira, nossa compreensão de identidade referente aos imigrantes, que inicialmente construímos, estava restrita aos nossos espaços sociais e, principalmente, restrita aos grupos étnicos com os quais tínhamos contato. Consequentemente, considerávamos, por exemplo, que um italiano era, de fato, um italiano simplesmente pelo fato de fazer parte de uma família naturalmente italiana, "comprovada" pelo sobrenome. Havia, portanto, a noção, naquele momento, de não-problematização de conceitos e de perspectivas, de que a identidade estava exclusivamente associada a fatores mais "objetivos" (sobrenomes, comidas, danças, festas), a práticas culturais que podem - porém não necessariamente - ser constitutivos da identidade.

Esta percepção, entretanto, não é incomum. Como pondera Penna (1998, p. 93), a identidade social é, na maioria das vezes, "tida como algo dado, inerente a um grupo ou indivíduo". No entanto, depois de momentos de reflexão crítica com base em vários autores (HALL, 1998; CUCHE, 2002; BAUMAN, 2005; MAHER,

2 A autora deste artigo é neta de imigrantes japoneses que vieram ao Brasil e estabeleceram bases na cidade de Curitiba no Paraná e São Paulo, capital. O co-autor, por sua vez, também é neto de japoneses que vieram ao Brasil no início de 1900, na cidade de Itápolis, interior do estado de São Paulo. 
2007; SILVA, 2000; WOODWARD, 2000; entre muitos outros) e de conhecer mais a fundo as diferentes histórias de nossas famílias, compreendemos que as relações entre os imigrantes nem sempre foram amigáveis e que a abertura ao fluxo imigratório, principalmente aos japoneses, atendeu aos interesses políticos e econômicos da política brasileira vigente.

O preconceito racial, a manipulação dos estereótipos (BHABHA, 2005), as perseguições aos estrangeiros, as proibições do ensino das línguas estrangeiras durante o governo Vargas são fatos presentes em vários documentos como jornais, decretos e artigos da Constituição brasileira que revelam o conflito de interesses da sociedade da época sobre a identidade japonesa, sobretudo no Sul do Brasil. ${ }^{3}$

Assim, a partir destas considerações, este trabalho tem por objetivos fazer um breve relato da imigração japonesa no Brasil e discutir a manipulação do estereótipo nipônico construído pela política de imigração da época. Também buscamos refletir sobre movimentos de trânsito e mobilidade sob a perspectiva dos estudos da linguagem, interessando-nos, portanto, as múltiplas relações entre língua, linguagens, identidade, cultura e outros fatores atrelados a questões migratórias.

\section{IDENTIDADE E CULTURA EM MEIO ÀS POLÍTICAS LINGUÍSTICAS NA HISTÓ- RIA DA IMIGRAÇÃO JAPONESA NO ESTADO DO PARANÁ ${ }^{4}$}

A história do Estado do Paraná não pode ser contada sem referência aos imigrantes europeus, uma vez que eles foram usados a construir a imagem de um lugar receptivo, no qual todos convivem de forma "harmoniosa" e isento de conflitos. Sabe-se que as regiões sul e sudeste do Brasil foram as que mais receberam levas de imigrantes, principalmente europeus, desde o período pós-independência, com o objetivo de colonizar uma área despovoada e alvo de disputa dos países vizinhos, como o Uruguai e Paraguai (no caso da região sul). Segundo dados do IBGE de 2000, estima-se que desde o período da pós-independência até os dias atuais, mais de 4 milhões chegaram pelo porto de Santos.

3 É importante salientar que outras imigrações (alemã, italiana, etc) também sofreram humilhações semelhantes no mesmo período.

4 Conforme já mencionado, as reflexões aqui apresentadas foram motivadas por nossas histórias de família, ambas de origem japonesa, porém com distintos percursos de imigração e estabelecimento em duas partes diferentes do Brasil. Considerando, então, as limitações de espaço/extensão deste gênero, optamos por discutir questões migratórias, linguísticas e identitárias relativas apenas ao contexto sócio-histórico e geopolítico do Estado do Paraná. 
No que diz respeito à imigração japonesa, há dados relativamente divergentes, em áreas diversas, conforme aponta Makino (2010). Os trabalhos de Leão Neto (1989), Nucci (2000), Sakurai (2000), Wawzyniak (2004), Kimura (2006) e Endrica (2007), dissertações de mestrado e teses de doutorado nas áreas de Sociologia, História, Geografia e Filosofia, nos fornecem informações históricas sobre as diferentes fases da imigração. Porém, poucos são os trabalhos da área da Linguística Aplicada que tocam em questões relacionadas à identidade do imigrante japonês, como o de Ginde (2009), que aborda mais especificamente a vida dos dekasseguis. ${ }^{5}$

Todavia, os referidos pesquisadores são unânimes em afirmar que 1908 é o marco da imigração japonesa no Brasil. Segundo registros oficiais, 165 famílias vieram em busca de melhores condições de trabalho e promessas de possuir terras férteis ${ }^{6}$. De acordo com Sousa (2007), as propostas do governo brasileiro eram, a princípio, muito melhores do que as condições enfrentadas por muitos deles em um país em crise, sem perspectiva de uma vida melhor. Como consequência,

Ir para o Brasil, fazer dinheiro nas lavouras de café e retornar ao Japão o mais breve possível não era um sonho para muitas famílias no início do século XX: era a única saída. Naquele tempo, o Japão era uma nação exaurida pela explosão populacional e pelos gastos provocados por guerras contra a China e a Rússia. (MAGALHÃES, 2007, p. 82, apud SOUZA, 2007, p. 120, grifo nosso)

Todavia, a promessa de uma vida em um país promissor não vinha somente do governo brasileiro. Segundo Souza (2007, p. 119), o governo japonês também "[...] estimulou a migração nipônica para outros países, em especial o Brasil, pela dinâmica do complexo cafeeiro que precisava de trabalhadores assalariados."

Percebe-se, então, o interesse em exportar e importar a mão de obra por parte do governo japonês e brasileiro, respectivamente. Além disso, os órgãos do governo brasileiro responsáveis por justificar a importância dessa mão de obra aproveitaram-se das características daquilo que se entende por "o estereótipo japonês", aos quais comumente se relacionam a disciplina, a calma, a submissão e a dedicação ao trabalho, além da experiência na agricultura, para reforçar o perfil do trabalhador mais adequado ao país.

Nota-se, então, que, inicialmente, as características tidas como positivas foram o pretexto brasileiro para justificar esse fluxo imigratório.

\footnotetext{
5 Termo usado para definir os brasileiros, descendentes de japoneses, que se "[...] deslocaram para o Japão, com o objetivo de trabalhar temporariamente e voltar em melhores condições econômicas [...] (GINDE, 2009, p.10)

6 Ver Wawzyniak (2004).
} 
Após a chegada do primeiro grupo de imigrantes japoneses ao Brasil em 1908, o governo japonês passa a subsidiar a fundação de colônias em São Paulo, local onde todas as famílias desembarcavam e eram encaminhadas para as fazendas de café do interior do Estado, e funda a BRATAC (Sociedade Colonizadora do Brasil LTDA) em 1928, antes conhecida como Federação das Cooperativas Imigratórias ao Exterior. Vinculada ao governo, esta era "[...] a entidade central unificadora das colônias japonesas no país em fase de formação. Além disso, a BRATAC era a responsável por recrutar e enviar para o Brasil colonos proprietários" (DEZEM, 2008, p.14).

Parece-nos claro, mais uma vez, que a política japonesa não era indiferente ao fluxo emigratório, pois tinha interesses em manter relações diplomáticas em terras brasileiras e, evidentemente, contornar seu problema populacional.

É extremamente importante perceber que muitas políticas imigratórias ignoravam os efeitos sociais do processo imigratório para as relações interculturais entre os imigrantes japoneses, imigrantes de outras nacionalidades e os brasileiros. $\mathrm{Ou}$, em um nível ainda mais problemático, essas políticas eram fundamentadas na noção de que todos os estrangeiros iriam facilmente se adaptar ao novo país e aos seus costumes, e conviver de forma pacífica com os outros que já estavam aqui.

Além disso, tais políticas idealizavam os imigrantes como sujeitos que abandonavam seus países, suas raízes, abriam mão de suas identidades e, felizes, aceitariam passivamente uma nova identidade brasileira, as condições precárias da viagem de navio e uma nova morada em antigas senzalas abandonadas das fazendas cafeeiras. Como resultado, existia a noção de que os imigrantes eram sujeitos "homogêneos" que tinham em comum os mesmos objetivos de vida.

É evidente, em nossa visão, que os posicionamentos políticos são equivocados e foram dificultadores do estabelecimento de posições mais críticas e menos "ingênuas" no que se refere ao relacionamento do imigrante com o outro. Não é surpreendente que, a partir dessas perspectivas, estereótipos diversos tenham sido criados acerca da imagem do imigrante e do cidadão japonês - muitos dos quais persistem até hoje, já que parecem estar fundados em uma concepção de identidade coletiva fixa, como se todos os indivíduos pudessem ser reduzidos a uma concepção de identidade que não oferece espaços para individualidades ou idiossincrasias (SERCU et al, 2005, apud PENNYCOOK, 2012, p. 42).

Nessa direção, ao argumentar que o construto de identidade não pode ser compreendido exclusivamente no âmbito de elementos físicos (cor de pele, altura, cor dos olhos, por exemplo) ou de somente algumas práticas culturais (culinária, vestuário, etc.), Fochzato (2010) destaca que identidade não tem um valor "estanque" ou "estático", pois sua compreensão é sempre negociada por meio do discur- 
so. Com isso, faz-se pertinente o que pontua a autora: "No momento em que se define determinada identidade por algum de seus traços (comportamento estereotipados, língua, ritos...) nega-se a possibilidade de compreender a fusão/alteração sociocultural" (FOCHZATO, 2010, p. 59).

Da mesma maneira como a negação da "fusão/alteração sociocultural" é problemática, a ideia da existência de um imigrante "homogêneo" também é rasa, pois está fundamentada na hipótese de uma "cultura nacional" que unifica e simplifica todos os membros em busca da construção de uma impressão generalizada de identidade cultural (HALL, 1998, p. 59). Falta, para a problematização dessa visão, a compreensão de que a identidade de um sujeito não é monolítica: ela é cortada por várias outras identidades - de raça, de religião, de sexo, de gênero - que, em um constante confronto, confluem para aquilo que o indivíduo entende e diz ser a(s) sua(s) identidade(s). Porque, também é preciso ressaltar, o pertencimento a determinadas culturas e identidades não é uma verdade absoluta; trata-se de representações que estão em níveis discursivos, representações que são, como sugere Maher (2007), "construções discursivas". Nesse sentido, entendemos a identidade (social, cultural) como um construto ideológico representada simbolicamente por meio do discurso.

Sendo assim, é no discurso e, consequentemente, em diversas formas de linguagem que posicionamentos ideológicos e políticos se materializam. No caso de representações sobre cultura e identidade de imigrantes japoneses no Brasil, também devemos considerar que tais conceitos são, muitas vezes, expressões do "imaginário" popular comum. A esse respeito, Fairclough (2010, p. 443) afirma:

\footnotetext{
Discursos incluem não somente representações sobre como as coisas são, mas também podem ser representações de como as coisas poderiam ser, ou 'imaginários'. Eles podem representar ou imaginar teias interconectadas de atividades, instrumentos, objetos e sujeitos em relações sociais, tempos e lugares, valores, etc. ${ }^{7}$
}

Tomando, portanto, a ideia de que discursos são representações posicionadas e abrangem imaginários multifacetados, também argumentamos a favor de uma definição de identidade que só pode ser compreendida em meio a um processo relacional: é por meio de relações dialéticas que chegamos a um entendimento daquilo que somos (ou acreditamos ser). É nesse sentido que tratar de identidade não se resume a "verdades absolutas", mas a

\footnotetext{
7 No original: "Discourses include not only representations of how things are, they can also be representations of how things could be, or 'imaginaries'. They can represent or imagine interconnected webs of activities, instruments, objects, subjects in social relations, times and places, values, etc."
} 
uma análise de discursos, de representações e de posicionamentos por meio dos quais as pessoas expressam relações de identificação. Isso revela que o conceito de identidade não é simples ou passível de ser resumido em uma noção homogeneizada. Revozeando Cuche (2002, p. 183): "Não há identidade em si, nem mesmo unicamente para si. A identidade existe sempre em relação a uma outra. Ou seja, identidade e alteridade são ligadas e estão em uma relação dialética. A identificação acompanha a diferenciação".

Vale destacar, ainda, que a ideia superficial de que imigrantes - não apenas no caso de japoneses no Brasil, mas em quaisquer outros contextos - conviveriam de forma pacífica na "terra nova" também desconsidera a possibilidade - e probabilidade - de conflitos tanto políticos (embasados em questões identitárias, linguísticas, históricas) como físicos, e falham em evidenciar que o contato e o diálogo com o outro em situações de negociação de diferenças, de valores e de posições "é competitivo, é tenso, é difícil" (MAHER, 2007, p. 265).

Outras ações políticas orientadas por noções simplificadoras e essencialistas (CUCHE, 2002) de cultura e identidade continuaram a ocorrer no decorrer da imigração japonesa no Brasil. No período após a $1^{\mathrm{a}}$ Guerra Mundial, o fluxo de imigrantes de várias nacionalidades se intensificou. Já na $2^{a}$ Guerra Mundial, embora o país não tenha se envolvido diretamente, o governo Vargas reproduziu a exaltação nacionalista das ditaduras alemã e italiana. A chamada Era Vargas (1930-1045), entre outras características, foi marcada pela xenofobia e, uma das medidas drásticas para evitar que os imigrantes (não só os japoneses) se mantivessem isolados em suas colônias foi a imposição da política de assimilação à cultura brasileira. ${ }^{8}$

O Artigo 121, $\$ 7^{\circ}$ da Constituição de 1934 passou a proibir a concentração de imigrantes em qualquer ponto do país e deixou claro que todos deveriam adaptar-se aos costumes brasileiros ${ }^{9}$. Houve, também, outras sanções que ilustram claramente a ideologia xenófoba e etnocêntrica, como relata Makino (2010, p.89-90, grifos nossos)

(...) a proibição do ensino de língua estrangeira para menores de 14 anos, o uso obrigatório e exclusivo de material de língua portuguesa no ensino primário e secundário, obrigatoriedade de ser brasileiro

8 Estudiosos como Sérgio Buarque de Holanda criticam a construção da identidade nacional na Era Vargas, conforme aponta Candido (1998). No entanto, por questões de tempo e espaço, não aprofundaremos esta discussão.

9 "É vedada a concentração de imigrantes em qualquer ponto do território da União, devendo a lei regular a seleção, localização e assimilação do alienígena". Disponível em: www. camara.gov.br/sileg/integras/115236.doc. Acesso em: 27 jun.2011. 
nato para ministrar aulas, ensino compulsório de história, geografia e civismo brasileiro, construção de escolas brasileiras em regiões com muitos estrangeiros, subsídios às escolas nacionais próximas à colônia, criação de grupos patrióticos de educação física e esporte, convocação de filhos de estrangeiros para servirem ao exército e a proibição de publicação em língua estrangeira (à exceção daquelas autorizadas por órgãos específicos).

Com base no que apresenta Makino (2010), muitos são os indícios de que, na época, havia uma política de tentativa de apagamento e silenciamento de identidades e vozes, entremeadas por um jogo político de poder que, evidentemente, favorecia apenas um grupo: o dominante (ou seja: os «não-imigrantes»). A menção aos «órgãos específicos» também deixa claro que, nas relações de poder travadas entre autoridades e imigrantes, havia uma hierarquia rigidamente estabelecida, para a qual dever-se-ia oferecer respeito e pedir «autorização».

A proibição de uso de língua estrangeira (língua dos imigrantes) representa, a nosso ver, além de uma tentativa de opressão ideológica do imigrante em relação às suas raízes, à sua terra natal, uma medida pouco pertinente e, pelo menos na nossa visão, descabida de protecionismo da identidade nacional brasileira em direção à construção daquilo que seria a «identidade linguística brasileira» (MARIANI, 2011, p.111, apud HOFFNAGEL, 2010, p. 103), representada simbolicamente no uso exclusivo (e excludente) da língua portuguesa. Afinal, seria possível medir o uso de uma língua ou de outra? Como se define o que constitui, de fato, «a língua portuguesa»? Seria, nesse caso, a língua uma ferramenta material e palpável, elemento estanque capaz de ser «manuseado» e «blindado» do efeito de estrangeiros?

Parece-nos evidente, assim, o impacto que algumas medidas políticas têm sobre as configurações, constituições e movimentos de identidades. Em outras palavras, como discute Blackledge (2005), língua e linguagem assumem papel fundamental na tentativa de «controle» de uma possível «identidade nacional» que atravessa políticas linguísticas, planejamento de línguas, ensino de línguas (para imigrantes), avaliação de línguas (para imigrantes), entre muitos outros procedimentos que tendem à opressão e ao silenciamento de vozes, culturas e identidades.

Está claro que essas visões de língua, cultura e identidade estão orientadas por perspectivas «mono»: monolíticas, monolíngues, monoculturais, pouco pertinentes em um país plural - plurilíngue e multicultural - como o Brasil. É por isso que consideramos imperativo que posições generalizadoras e etnocêntricas sejam discutidas, tanto no que se refere a relações interculturais quanto intraculturais, pois o que se vê, na prática, ainda é o domínio de desigualdades, preconceitos e extremismos dentro do mesmo país, sobretudo em relação ao silenciamento de grupos minoritários, à desvalorização de suas práticas culturais em detrimento da valorização de práticas culturais legitimadas (música, literatura, cinema do mains- 
tream), à desconsideração das muitas línguas (indígenas, de imigrantes, LIBRAS) que compõem, de fato, a "identidade linguística brasileira", à redução das culturas de imigrantes, do outro, nas práticas pedagógicas tanto em língua materna quanto em língua estrangeira, levando ao desenvolvimento de estereótipos culturais; entre muitos outros problemas.

Políticas totalizadoras, como a descrita por Makino (2010), parecem sugerir "[...] a ideia de um Brasil monolíngue e civilizado (leia-se uma identidade europeia e não americana), efetivamente silenciando os povos indígenas, africanos e outros que com a imigração deram sua contribuição à língua e à cultura brasileira" (HOFFNAGEL, 2010, p. 105).

Essas deliberações, portanto, parecem estar fundadas em perspectivas contrárias às noções de mesticismo e hibridismo ${ }^{10}$. Esses conceitos, segundo Pennycook (2012), se opõem a registros essencialistas de cultura e identidade que focalizam o purismo, a imutabilidade, a rigidez e solidez tanto de línguas quanto de culturas. Essa é uma visão que, segundo García Canclini (2008, p. XXI), tem origens «em uma crença do século XIX, quando a hibridação era considerada com desconfiança ao supor que prejudicaria o desenvolvimento local».

Ressaltamos, mais uma vez, que essa perspectiva é, a nosso ver, incompatível com as constantes interpenetrações de línguas, culturas e identidades que ocorrem a todo momento, talvez em níveis inconscientes, em diversos ambientes (presenciais e virtuais) de relacionamento humano mediados simbolicamente pela linguagem.

As discussões no Congresso Nacional continuaram depois do período Vargas e, em uma das discussões para elaboração da Constituição de 1946, a entrada de novos imigrantes japoneses no país foi motivo de divisão de partidos. A discussão somente foi encerrada quando o presidente da assembleia deu o voto de Minerva em favor da entrada dos imigrantes, como expõe a socióloga Sakurai (2008) em entrevista ao jornal da Unicamp.

Se na elaboração dos artigos da Constituição as discussões sobre políticas imigratórias eram acirradas, elas também continuavam entre outros membros da alta sociedade da época, como os empresários e fazendeiros do café.

Apesar da propaganda em torno do estereótipo japonês, as características positivas não foram fator de aceitação. Algumas informações que chegavam aos ouvidos de pessoas influentes das sociedades paulistana e paranaense por meio de jornais e rádio os alertavam para o «perigo» dos asiáticos em terras tropicais. Um

10 Defendemos, neste trabalho, a definição de García Canclini (2008, p. XIX) acerca do conceito de hibridação: "processos socioculturais nos quais estruturas ou práticas discretas, que existiam de forma separada, se combinam para gerar novas estruturas, objetos e práticas". 
exemplo é a publicação d'O Jornal do Comércio, em 11 de janeiro de 1938, com a seguinte manchete: "Um perigo para a nacionalidade: a imigração japonesa"11, cuja mensagem deixava clara a preocupação das autoridades brasileiras com a possibilidade ilusória de "degradação" ou "descaracterização" da identidade social e cultural do Brasil mediante a entrada de imigrantes japoneses no país.

Mais emblemática é a ideia de que a mistura de raças, culturas e práticas culturais pudesse representar um "perigo" para a nacionalidade "pura". Ainda que se entenda que processos de mestiçagem, sincretismo, crioulização e hibridação não ocorrem sem conflitos ${ }^{12}$, esses conceitos são os que, na nossa visão, mais nos auxiliam a compreender, de forma ampla e crítica, o processo de imigração japonesa no Brasil. Porque, como avalia García Canclini (2008, p. XXVIII), principalmente a noção de hibridação "[...] pode ajudar a dar conta de formas particulares de conflito geradas na interculturalidade recente em meio à decadência de projetos nacionais de modernização na América Latina".

A hipótese de que a imigração japonesa pudesse representar um "perigo" àquilo que se entende por "nacionalidade brasileira" está de acordo com o que Blackledge (2005, p. 20) chama de "discurso político discriminatório", no qual as representações sobre o "eu" são construídas de maneiras positivas, colidindo com representações geralmente negativas sobre o "outro", evidenciando um processo que acarreta, invariavelmente, na criação de estereótipos, exclusões e discriminações.

Outras informações que também chegaram voltavam-se para as "[...] experiências malsucedidas nos EUA e outros países com a imigração chinesa e os efeitos sociais [...] indesejados como a formação de quisto e a formação de locais somente com estrangeiros, considerados impassíveis de assimilação pelos países hospedeiros" (MAKINO, 2010, p.9). Naquela época, e talvez exista ainda hoje, a generalização problemática e duvidosa de uma única identidade asiática para japoneses, chineses, vietnamitas, cambojanos, etc. Logo, se alguns imigrantes chineses formavam guetos nos EUA, havia uma extensão do mesmo raciocínio para a possibilidade (talvez a certeza) de que, no Brasil, os japoneses não fariam diferente. É claro, portanto, que, de fato, o pensamento das sociedades paulistanas e paranaenses refletia a preocupação política daquele momento histórico brasileiro.

A sociedade paranaense, por exemplo, em consonância com a política do "imigrante ideal" que tinha na figura do europeu a imagem do mais adequado para o embranquecimento nacional, iniciou uma campanha anti-nipônica. Por serem asiáticos ou povos amarelos, seus atributos físicos como a baixa estatura, olhos puxados e de

11 apud MAKINO, 2010, p.28.

12 Ver García Canclini (2010). 
cor escura, e pele amarela não eram vistos como equiparáveis à alta estatura, olhos claros e pele clara dos alemães, poloneses e italianos. Cabe ressaltar, aqui, que as características até então vistas como positivas usadas em favor dos japoneses foram revertidas em prol, mais uma vez, da pureza e do protecionismo da idealização da identidade social e cultural do brasileiro.

Os adjetivos relativos à personalidade deram lugar aos adjetivos de descrição física incompatíveis com o idealizado padrão europeu. Mais interessante ainda é pensar que esta concepção restrita sobre o imigrante ideal generalizava todas as pessoas de uma mesma cultura e as enquadrava em padrões identitários e físicos idênticos, como se não houvessem variações em uma mesmo grupo, desconsiderando, por exemplo, a possibilidade de existência de alemães baixinhos, de pele e olhos escuros, por exemplo.

Estava em jogo, naquele ponto, a estereotipia e a rotulação de grupos inteiros, processo perigoso para o estabelecimento de noções mais críticas de cultura e identidade, porque ignorava a possibilidade de individualidades, de diferenças intraculturais. O dizer de Cox e Assis-Peterson (2007, p. 30) corrobora essa nossa posição:

\begin{abstract}
[...] ser membro de uma mesma cultura não significa ter conhecimento idêntico. Pessoas de uma mesma comunidade e até de uma mesma família podem ter ideias diferentes sobre crenças culturais, habilidades diferentes nas práticas cotidianas e estratégias diferentes para interpretar e resolver problemas. [...] A língua nos fornece rótulos que muitas vezes são aceitos como dados. Falamos de 'americanos', 'italianos', 'japoneses', como se fossem grupos monolíticos.
\end{abstract}

Os ataques aos imigrantes japoneses veiculados pela mídia repetiam a ideia do perigo amarelo ${ }^{13}$ em referência à cor da pele ou perigo alienígena ${ }^{14}$, termo que tem duplo sentido: pode tanto significar um sujeito estrangeiro ${ }^{15}$ quanto um ser estranho, pertencente a uma outra cultura e país estranhos e, por ser diferente, inapto para viver na mesma sociedade que os demais ${ }^{16}$. Assim, essas ideias reforçam como a diferença ou o fato de os imigrantes não compartilharem os mesmos atributos desejáveis para a época foram motivo de exclusão.

Outro acontecimento que marca negativamente a presença dos imigrantes japoneses no Paraná foi uma medida política adotada pelas delegacias

\footnotetext{
13 Destaque nosso.

14 Destaque nosso.

15 Em língua inglesa, o termo alien também se refere aos estrangeiros.

16 Os termos perigo amarelo e perigo alienígena também aparecem nos títulos dos trabalhos de KIMURA (2006) e ENDRICA (2007), respectivamente.
} 
regionais de Antonina e Paranaguá, cidades do litoral do estado. Depois que o Brasil declarou guerra ao Japão, os japoneses que viviam nas regiões mencionadas foram expulsos do país em 25 de setembro de 1942, sob a justificativa de que eram espiões do inimigo. Contudo, apesar da não-aceitação, da expulsão e das sanções, a política imigratória brasileira continuou recebendo novos imigrantes japoneses. Até 1950, calcula-se que mais de 15 mil ${ }^{17}$ vieram em direção à capital e norte do Paraná, onde compraram lotes da "Companhia de Terras Norte do Paraná" na década de 30 em diante, e seus descendentes continuam até hoje nessas terras.

Parece-nos evidente, portanto, que ao longo do processo de imigração e em meio a políticas orientadas por noções de marginalização, exclusão e preconceito, a identidade de imigrantes japoneses foi estigmatizada e atravessada por medidas de silenciamento (de voz, de cultura, de língua). Primeiro, os imigrantes japoneses foram considerados inadequados por não terem a aparência física desejada para permanência em terras brasileiras, julgados como inferiores, e depois foram acusados de serem criminosos, embora faltassem provas (ENDRICA, 2007). Essa identidade negativa, construída pela política de imigração e perpetuada por parte da sociedade brasileira, nos explica Cuche (2002, p. 185), é "[...] como uma identidade vergonhosa e rejeitada em maior ou menor grau, o que se traduzirá muitas vezes como uma tentativa para eliminar, na medida do possível, os sinais exteriores da diferença negativa."

A mudança na concepção do estereótipo nipônico de "adequado" para "indesejável" ou representando "perigo" à nacionalidade brasileira nos faz pensar sobre o caráter manipulatório da mídia, principalmente jornais, no que se refere ao tratamento atribuído às identidades dos imigrantes japoneses na época do fluxo imigratório no Brasil. Nessa direção, cabe questionar quem seriam os imigrantes que vivenciaram a estereotipificação conveniente aos objetivos políticos do governo varguiano.

Um dos trabalhos que nos ajuda a compreender a construção (e desconstrução) dessas identidades é a pesquisa de Ocada (2006) - embora não aborde especificamente os imigrantes no Paraná. Sua válida contribuição vem dos relatos de mulheres idosas de famílias nipo-brasileiras que reconstroem, por meio do discurso, suas memórias.

17 Segundo dados do site do IBGE disponíveis no site:http://www.ibge.gov.br/brasil500/ japoneses/ destinoimig.html>. Acesso em: 27 jun.2011. 
Um dos argumentos da pesquisa é a problematização da imagem do imigrante nipônico por parte das entrevistadas. Segundo os relatos orais analisados, nem todos os imigrantes eram agricultores ou estavam dispostos a criar novas raízes no Brasil. Aqueles que não tinham experiência na agricultura eram forçados a aprender, ao passo que muitos não pretendiam permanecer, pois acreditavam que a estadia seria temporária, até conseguirem juntar dinheiro para voltar ao país de origem, motivo pelo qual, de acordo com os dados dessa pesquisa (OCADA, 2006), eles não se preocupavam em aprender a língua e em participar de práticas culturais brasileiras.

Sabe-se também que o choque cultural decorrente da dificuldade com o aprendizado da língua portuguesa, a adaptação ao clima e aos hábitos alimentares brasileiros pioravam a perspectiva de viver no país. Ademais, como eram praticamente escravizados pelos donos das grandes fazendas de café e, de certa forma, substituíram os escravos negros (MEAGHER, 1975, apud MAKINO, 2010, p.10.), não foram poucas as histórias de suicídios, fugas noturnas das famílias de São Paulo para o Paraná e greves.

Portanto, com base nos relatos do grupo pesquisado por Ocada (2006), o estereótipo positivo inicialmente propagado pelas políticas migratórias não parece ter prevalecido, cedendo lugar rapidamente a imagens negativas - e mais problemáticas - do imigrante japonês. Neste ponto, é necessário ponderar que os relatos individuais analisados pelo autor são experiências, memórias e lembranças que não podem ser generalizadas, mas são interpretações de um momento ou de vários momentos que nos ajudam, sob a nossa perspectiva, a obter uma breve compreensão de quem eram estes imigrantes.

Novamente, vale a ressalva de que as percepções sobre o estereótipo do japonês contidas nos relatos aos quais nos referimos (OCADA, 2006) e presente, também, nas ações políticas discutidas ao longo deste texto são construções discursivas que revelam as representações de um determinado grupo de pessoas, em meio a um determinado contexto sócio-histórico, acerca de questões de cultura e identidade.

Nesse sentido, o estereótipo, segundo Bhabha (2005), é usado como estratégia para reforçar diferenças culturais, construindo uma "imagem congelada" do outro. E, considerando que não acreditamos na possibilidade de avaliar cultura e identidade com base em binarismos ("verdadeiras ou falsas", "boas ou ruins", "certas ou erradas", etc.), somos levados a crer, ao lado de diversos autores, que esses conceitos não são rasos ou cabíveis em compreensões essencialistas e extremistas, geralmente reduzidas a estereótipos. Desta forma, concordamos com García Can- 
clini (2008, p. XXIII): "Não é possível falar das identidades como se tratasse apenas de um conjunto de traços fixos, nem afirmá-las como a essência de uma etnia ou de uma nação".

Atualmente, o Paraná, juntamente com São Paulo, é um dos Estados com maior concentração de descendentes dos imigrantes japoneses que trazem consigo suas histórias de viagens, mobilidades, mudanças e constantes adaptações em diferentes espaços. Essa parte da história na formação regional do Brasil nos faz refletir sobre a manipulação do estereótipo nipônico durante o governo de Vargas no Paraná e traz à tona o pensamento de Woodward (2000) de que a identidade é marcada pela diferença.

Neste trabalho, a identidade do imigrante japonês foi marcada pela diferença, pelo estereótipo, pela generalização de personalidade e depois física. Mais importante ainda é ver que a diferença esteve relacionada com a eliminação, no caso dos imigrantes expulsos do litoral do Paraná, ou com a proibição de chegada novos imigrantes. A esse respeito, a autora conclui que: "A diferença é marcada pela exclusão, mas parece que algumas diferenças - neste caso entre grupos étnicos - são vistas como mais importantes que outras, especialmente em lugares particulares e em momentos particulares" (WOODWARD, 2000, p.11).

Tal afirmação nos parece oportuna para resumir a condição do imigrante japonês no período de 1930-1945: primeiramente, considerado importante para trabalhar na agricultura; depois, tido como inadequado para viver no Brasil por representar um "perigo" à identidade nacional. Do ponto de vista do governo, o imigrante era útil, desde que atendesse ao perfil da época e, para o imigrante, o lugar de chegada era importante, desde que oferecesse as mínimas condições de sobrevivência. Deste modo, está claro que em meio a contradições, conflitos e múltiplos olhares, não há somente uma perspectiva ou uma única história sobre a imigração japonesa, até porque, como sabiamente questiona Woodward (2000, p. 250): "Existe uma verdade histórica única que possa ser recuperada?".

Assim, tomamos como certo que o estudo de questões identitárias perpassa, de maneiras diversas, estudos sobre discurso, pois como afirma Blackledge (2005, p. 36): "Identidades são compreendidas, aqui, como produzidas e legitimadas no discurso e na interação social, e como múltiplas, dinâmicas e sujeitas a mudança." 18

18 No original: "Identities are here conceptualized as produced and legitimized in discourse and social interaction, and as multiple, dynamic, and subject to change." 


\section{MOBILIDADE, DESLOCAMENTOS E IDENTIDADE}

O estudo de histórias da imigração japonesa no Brasil e das ramificações desse processo para o desenvolvimento de estereótipos culturais em relação aos imigrantes japoneses nos leva a acreditar que as mobilidades desses imigrantes não se restringem a um plano físico ou geográfico. Esses movimentos migratórios têm implicações para as identidades dos imigrantes, isto é, para a maneira como suas identidades são representadas através de construções discursivas oriundas tanto dos próprios imigrantes como das medidas políticas que apresentamos e discutimos no item anterior.

Isto porque, como sugere Pennycook (2012, p. 45), não são apenas os processos de imigração, mas também as viagens e nossos encontros com o diferente que podem resultar tanto em uma jornada para o interior de nós mesmos, de nossas comunidades e daquilo que entendemos ser as nossas culturas, quanto para qualquer outro lugar ${ }^{19}$.

Parece-nos, nesse sentido, que mobilidades, sejam elas com destinos específicos ou não, guardadas as suas causas motivadoras, não ocorrem sem que existam rupturas - de laços, de afetividades, de familiaridades. Sobretudo quando são permeadas por conflitos históricos, políticos, sociais e culturais, como é o caso de percursos de imigração, torna-se ainda mais claro que os deslocamentos físicos são apenas um dos fatores propulsores do desenvolvimento de outros confrontos, especialmente aqueles mediados pela linguagem, como a construção de estereótipos culturais, o enfrentamento de políticas de repressão de uso da língua materna do imigrante, o choque cultural em face da mudança para uma nova terra, entre muitos outros.

Endossamos, portanto, a posição de Penna (1998, p. 106) quando a autora define que "[...] as andanças de um migrante, em seus sucessivos deslocamentos, constituem um contínuo processo de transformação - destruição e recriação [...]".

Há de se deixar claro, neste ponto, que a mobilidade e seus movimentos estão sempre ligados a relações de poder. Como vimos com a história da imigração japonesa no Estado do Paraná, os deslocamentos de imigrantes eram controlados - incentivados, permitidos, negados - por instrumentos de poder materializados tanto na Constituição do Brasil quanto em medidas regionais, como no caso da expulsão de imigrantes japoneses em duas cidades paranaenses, conforme expusemos anteriormente.

19 No original: "We have long known, too, that travel, our encounters with the difference, may be a journey into ourselves as much as a journey elsewhere". 
O que está em jogo, quando se trata de trânsitos e mobilidades, é a disputa por poder e pelo controle da mobilidade. É sob essa ótica que Massey (1991) avalia o conceito de mobilidade, com o qual concordamos e reproduzimos aqui:

[...) ] trânsito e o controle sobre este refletem e reforçam poder. Não é simplesmente uma questão de má distribuição que faz com que algumas pessoas transitem mais do que outras, e que outras tenham mais controle do que outras. É porque o trânsito e o controle de alguns grupos podem progressivamente enfraquecer outros [grupos].

(MASSEY, 1991, p. 27, apud PENNYCOOK, 2012, p. 27) ${ }^{20}$

O controle de grupos minoritários exercido por grupos detentores de maior poder pode ser associado tanto às histórias de imigração, que discutimos neste artigo, quanto a outras relações marcadas pela desigualdade, como é o caso do tratamento recebido por comunidades indígenas no Brasil, por exemplo; ou quando pensamos na repressão, preconceito e violência - em escalas e condições diferentes - de outros grupos minoritários, como homossexuais, quando em contato (e confronto) com grupos de maior poder.

Os processos de mobilidades - sejam eles derivados de imigração ou não são, na nossa perspectiva, indicativos de transformação, geralmente permeados por conflitos, e expressados invariavelmente por meio da linguagem e seus símbolos.

Interessa-nos, neste ponto, destacar que os deslocamentos físicos têm consequências para deslocamentos discursivos, porque assim como Pennycook (2012, p. 27), entendemos que línguas e linguagens não são entidades que ficam paradas em um só lugar; elas são recursos móveis que se deslocam por diferentes locais, por meio de diferentes perspectivas. Língua não é, nessa visão, uma entidade estática: ela está intimamente ligada à constituição do sujeito e às suas identidades, que, da mesma maneira, não são pré-estabelecidas, rígidas ou fixas. Elas acompanham quaisquer mobilidades que venham a ocorrer.

Quando pensamos, então, nas tentativas do governo brasileiro de reprimir expressões sociais e culturais do imigrante japonês por meio da proibição de uso de sua língua materna, por exemplo, ou quando retomamos a manchete de jornal que descrevia a imigração japonesa como um "perigo" para a "nacionalidade brasileira", fica evidente que os conceitos de identidade embasando esses discursos eram equi-

20 No original: (...) mobility, and control over mobility, both reflects and reinforces power. It is not simply a questions of unequal distribution, that some people move more than others, and that some have more control than others. It is that the mobility and control of some groups can actively weaken other people. 
vocados. Havia a noção de que identidade e cultura seria um "objeto" que pudesse ser protegido ou descartado, como se fosse um "material" manipulável.

O que entendemos, ao lado de Penna (1998, p. 92-93) é que "identidade social é uma construção simbólica que envolve processos de caráter histórico e social, que se articulam (e atualizam) no ato individual da atribuição". Isso significa que, como já discutimos, a identidade social é melhor compreendida ao nível do discurso, pois é nele que ela é simbolicamente representada. Trata-se, então, de

\footnotetext{
uma representação, relativa à posição social, e portanto intimamente vinculada às questões de reconhecimento. Concebemos a possibilidade de múltiplas identidades, com base em referenciais distintos - como a origem territorial, a condição de gênero, a etnia, a atividade profissional, etc. -, pois, enquanto uma construção simbólica, a identidade não é decorrência automática da materialidade. (PENNA, 1998, p. 93)
}

Como vimos argumentando, as políticas de imigração, especialmente àquelas referentes aos japoneses no Brasil, eram orientadas por conceitos de identidade insuficientes para abranger as multiplicidades de raça/etnia, línguas, religiões existentes no país. Entre os conflitos e as dores que essas medidas provocaram, restaram apenas evidências de que elas fracassaram. Afinal, seria impossível, ao menos para nós, conceber uma identidade nacional e cultural brasileira sem os valores da cultura japonesa - e de tantos outros imigrantes e suas culturas.

Com isso, parece-nos claro que categorias pré-estabelecidas e fixas de identidade não servem a qualquer propósito a não ser gerar e registrar exceções. Isto porque nós, autores deste trabalho, seríamos, à vista das políticas de imigração japonesa no Brasil e dos conceitos de identidade nas quais suas ações se sustentam, exemplos significativos de "contradições": brasileiros com descendências japonesa, italiana e polonesa; não portadores de características físicas próprias dos europeus; estudantes, professores e falantes de línguas estrangeiras, que se interessam por publicações em língua estrangeira, mesmo sem pedir autorização a órgãos específicos.

\section{CONSIDERAÇÕES FINAIS}

Compreender o momento histórico da vinda dos imigrantes japoneses ao Brasil é também compreender a nossa própria história. Significa entender os diferentes motivos das vindas de nossas famílias do Japão para o Brasil, a preocupação em manter a língua e os costumes tradicionais durante e depois da xenofobia da era Vargas. Este processo nos mostra que, na história, 
[...] sempre há alguma coisa a explicar, desculpar, esconder ou, pelo contrário, corajosamente ostentar, negociar, oferecer, barganhar. Há diferenças a serem atenuadas ou desculpadas, ou pelo contrário, ressaltadas e tornadas mais claras. (BAUMAN, 2005, p. 19)

Finalmente, acreditamos nas palavras de Cuche (2000, p. 200) ao assegurar que "[...] participar de certa cultura particular não implica automaticamente ter certa identidade particular." Em outras palavras, participar da cultura japonesa não significa que sejamos "japoneses de fato", uma vez que não temos uma identidade fixa, única e homogênea. Além disso, conforme defendemos neste trabalho, nossa identidade só pode ser compreendida em meio às nossas representações, à maneira como nós nos entendemos e nos expressamos em nossos discursos. E, nesse sentido, nos parece impossível reduzir nossas identidades a rótulos como apenas "japoneses" ou "brasileiros", porque, ao que nos parece, o entendimento de quem somos vai além de generalizações e é atravessado por múltiplas práticas, por diversas identidades que se entrecortam e interpenetram continuamente.

Enquanto sujeitos, brasileiros, descendentes de japoneses, professores e, da mesma forma que Agnes Heller ${ }^{21}$, também sentimos que, por vezes, estamos sobrecarregados de identidades demais para uma pessoa. Talvez a metáfora do quebra-cabeça incompleto proposto por Bauman (2005) como analogia para falar das identidades do sujeito na pós-modernidade venha em bom momento: discutir sobre as identidades dos imigrantes japoneses no Brasil é uma biografia sem fim e não podemos usar o estereótipo manipulado pelas políticas da época de Vargas como se fosse a imagem impressa na caixa do jogo de quebra-cabeças a ser alcançada.

\section{REFERÊNCIAS BIBLIOGRÁFICAS}

ALVES FILHO, M. (2008). Da xenofobia pintada de amarelo ao quase silêncio. Jornal da UNICAMP, Campinas, 16 a 22 jun.2008. Olhar da UNICAMP sobre o centenário, p.3.

21 "Agnes Heller, com quem compartilho, em grande medida, os apuros da vida, uma vez se queixou de que, sendo mulher, húngara, judia, norte-americana e filósofa, estava sobrecarregada de identidades demais para uma só pessoa. Ora, seria fácil para ela ampliar a lista, mas os arcabouços de referência por ela citados já são suficientemente numerosos para demonstrar a impressionante complexidade da tarefa." (BAUMAN, 2005, p.19) 
BAUMAN, Z. (2005). Identidade - entrevista a Benedetto Vecchi. Tradução de Carlos Alberto Medeiros. Rio de Janeiro: Jorge Zahar Ed.

BHABHA, H. K. (2005). O local da cultura. Belo Horizonte: UFMG.

BLACKLEDGE, A. (2005). Discourse and Power in a Multilingual World. Amsterdam: John Benjamins Co.

BRASIL. Constituição 1934. Disponível em: www.camara.gov.br/sileg/integras/115236. doc. Acesso em: 27 jun.2011.

CANCLINI, N. G. (2003). Culturas Híbridas: estratégias para entrar e sair da modernidade. Tradução H. P. Cintrão; A. R. Lessa. São Paulo: EDUSP.

CANDIDO, A. (1998). A visão política de Sérgio Buarque de Holanda. In: CANDIDO, Antonio (org.) Sérgio Buarque de Holanda e o Brasil. São Paulo: Perseu Abramo.

COX, M. I. P.; ASSIS-PETERSON, A. A. (2007). Transculturalidade e Transglossia: Para Compreender o Fenômeno das Fricções Linguístico-Culturais em Sociedades Contemporâneas sem Nostalgia. In: CAVALCANTI, M. C.; BORTONI-RICARDO, S. M. (Orgs.). Transculturalidade, Linguagem e Educação. Campinas: Mercado de Letras, p. $23-43$.

CUCHE, D. (2002). A Noção de Cultura nas Ciências Sociais. Tradução de Viviane Ribeiro. (2a edição) Bauru: EDUSC.

DEZEM, R. (2011). Um exemplo singular de política imigratória: subsídios para compreender o processo de formação dos núcleos pioneiros de colonização japonesa no estado de São Paulo (1910- 1930). Disponível em: <http://usp.br/ proin/download/ artigo/artigo_politica_imigratoria.pdf>Acesso em: 27 jun. 2011.

ENDRICA,G. (2007). O "Perigo Alienígena": política imigratória e pensamento racial no governo Vargas (1930-1945). Tese de Doutorado em História. Instituto de Filosofia e Ciências Humanas, Unicamp, Campinas.

FAIRCLOUGH, N. (2010). Critical Discourse Analysis: the Critical Study of Language. Harlow: Longman.

FOCHZATO, M. A. S. (2010). Nós só conseguimos enxergar dessa maneira...: representações e formação de educadores. Tese de Doutorado em Linguística Aplicada. Instituto de Estudos da Linguagem, Unicamp, Campinas.

GINDE, B.T. (2009). Um estudo sobre a (re) inserção linguístico cultural e os conflitos identitários vivenciados por filhos de dekasseguis. Monografia de Graduação em Letras, Instituto de Estudos da Linguagem, Unicamp, Campinas.

HALL, S. (1998). A Identidade Cultural na Pós-modernidade. Rio de Janeiro: DP\&A.

HOFFNAGEL, J. C. (2010). Linguagem e poder: políticas linguísticas no Brasil. In: Temas em Antropologia e Linguística. Recife: Edições Bagaço, p. 99-112.

IBGE. Censo demográfico 2000. Migração e deslocamento. Resultados da Amostra. Disponível em: < http://www.ibge.gov.br/home/estatistica/populacao/censo2000 /migracao/censo2000_migracao.pdf.> Acesso em:27 jun.2011. 
LEÃO NETO, V.C. (1989). A crise da imigração japonesa no Brasil (1930-1934): contornos diplomáticos. Brasília: Fundação Alexandre Gusmão.

MAHER, T. M. (2007). A Educação do Entorno para a Interculturalidade e o Plurilinguismo. In: KLEIMAN, A. B.; Cavalcanti, M. C. (orgs.) Linguística Aplicada: faces e interfaces. Campinas, SP: Mercado de Letras, p. 255-270.

KIMURA, R. (2006). Políticas restritivas aos japoneses no Estado do Paraná (de cores proibidas ao perigo amarelo). Dissertação de Mestrado em História. UEM, Maringá.

MAKINO, R. (2010). As relações nipo-brasileiras (1895-1973): o lugar da imigração japonesa. Dissertação de Mestrado em Relações Internacionais. UnB, Brasília.

NUCCI, P. (2000). Os Intelectuais diante do racismo antinipônico no Brasil: textos e silêncios. Dissertação de Mestrado em História. Instituto de Filosofia e Ciências Humanas, Unicamp, Campinas.

NUCCI, P. (2011). O perigo japonês. Disponível em: <www.ifch.unicamp.br/ojs/index. php/ rhs/article/download/200/192.> Acesso em 27 jun 2011.

PENNA, M. (1998). Relatos de migrantes: questionando as noções de perda de identidade e desenraizamento. In: SIGNORINI, I. (org) Lingua(dem) e identidade: elementos para uma discussão no campo aplicado. Campinas, SP: Mercado de Letras, p. 89-112.

PENNYCOOK, A. (2012). Language and mobility: unexpected place. Bristol: Multilingual Matters.

OCADA, F.K. (2006). Uma reconstrução da memória da imigração japonesa no Brasil. Teoria \& Pesquisa, v.1, n.49, p. 141-164.

SAITO, H. (1961). O japonês no Brasil: estudo de mobilidade e fixação. São Paulo: Sociologia e Política.

SAKURAI, C. (2000). Imigração tutelada: os japoneses no Brasil. Tese de Doutorado em Antropologia. Instituto de Filosofia e Ciências Humanas, Unicamp, Campinas.

SOUSA, A.A. (2007). A territorialização dos imigrantes japoneses na Alta Sorocaba. Revista Formação, v.2, n.14, p. 119-129.

WAWZYNIAK, S.M.S. (2004). Histórias de estrangeiro: passos e traços de imigrantes japoneses (19081960). Tese de Doutorado em História, Setor de Ciências Humanas, Letras e Artes, UFPR, Curitiba.

WOODWARD, K. (2000). Identidade e Diferença: uma introdução teórica e conceitual. In: SILVA, T. t. (org.) Identidade e Diferença: a perspectiva dos Estudos Culturais. São Paulo: Vozes, p. 7-72.

Recebido: 11/10/2013

Aceito: 06/10/2014 